\section{Radioprotective Effects of Zinc and Selenium on Mice Spermatogenesis}

\author{
Bagheri H. ${ }^{1 \oplus}$, Salajegheh A. ${ }^{1}$, Javadi A. ${ }^{2}$, Amini P.3, Shek- \\ archi B. ${ }^{4}$, Shabeeb D. ${ }^{5}$, Eleojo Musa A. ${ }^{6}$, Najafi M.7.8*๑
}

\begin{abstract}
Background: Spermatogenesis system is one of the most radiosensitive organs in the body. A usual therapeutic dose of radiation such as the conventional 2 Gy in each fraction of radiotherapy and lower doses seen in diagnostic radiology or a radiation disaster affect the process of spermatogenesis potently. Selenium and zinc are two important elements playing key roles in the development of sperms and also have radioprotective effects.
\end{abstract}

Objective: In this study aims to evaluate the radioprotective effect of zinc and selenium against radiation-induced mice testis injury.

Material and Methods: In this experimental study, 30 mice were divided equally into 6 groups, including control selenium treated, zinc treated, radiation, radiation + selenium, radiation + zinc. Treatments started from 2 days before irradiation with 2 Gy cobalt-60 gamma rays. After 37 days, all mice were killed for histopathological evaluations.

Results: Results showed that exposure to radiation caused a potent effect on spermatogenesis system. Treatment with selenium reversed these radiation effects potently, while zinc had some limited protective effects. Zinc treatment itself caused a detrimental effect on epididymis and, in combination with radiation, it leads to more damage to seminiferous tubules.

Conclusion: In contrast to previous studies that proposed zinc to protect spermatogenesis against various toxic agents, results of this study showed that although zinc may protect from some parameters, it potentiates radiation damage on seminiferous tubules and has a detrimental effect on the epididymis. By contrast, zinc and selenium could alleviate radiation-induced toxicity on the most of the evaluated parameters.

Citation: Bagheri H, Salajegheh A, Javadi A, Amini P, Shekarchi B, Shabeeb D, Eleojo Musa A, Najafi M. Radioprotective Effects of Zinc and Selenium on Mice Spermatogenesis. J Biomed Phys Eng. 2020;10(6):707-712, doi: 10.31661/jbpe.v0i0. 957

\section{Keywords}

Radiation; Spermatogenesis; Zinc; Selenium; Seminiferous Tubules; Epididymis

\section{Introduction}

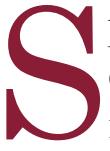
permatogenesis system is one of the most sensitive organs to various types of environmental toxic agents such as metals, non-ionizing and ionizing radiation [1]. The process of spermatogenesis procedure takes between 64 to 72 days in humans. This procedure takes place in the seminiferous tubules within the testis. In these tubules, the germ cells divide and produce spermatogonia, spermatocytes, spermatids, and finally mature spermatozoa. The high rate of division of these cells into the seminiferous tubules causes thier high sensitivity to toxic
${ }^{1} \mathrm{MSc}$, Radiation and

Wave Research Center,

Aja University of Medical

Sciences, Tehran, Iran

${ }^{2} \mathrm{MD}$, Department of

Pathology, Imam Hossein

Hospital, Shahid Beheshti

University of Medical Sci-

ences, Tehran, Iran

${ }^{3} \mathrm{MSc}$, Department of

Radiology, Faculty of Para-

medical, Tehran Univer-

sity of Medical Sciences,

Tehran, Iran

${ }^{4} \mathrm{MD}$, Radiation and Wave

Research Center, Aja

University of Medical Sci-

ences, Tehran, Iran

${ }^{5} \mathrm{PhD}$, Department of

Physiology, College of

Medicine, University of

Misan, Misan, Iraq

${ }^{6} \mathrm{MSc}$, Research Center

for Molecular and Cellular

Imaging, Tehran Univer-

sity of Medical Sciences

(International Campus),

Tehran, Iran

${ }^{7}$ PhD, Medical Technology

Research Center, Kerman-

shah University of Medical

Sciences, Kermanshah,

Iran

${ }^{8} \mathrm{PhD}$, Radiology and

Nuclear Medicine Depart-

ment, School of Paramed-

ical Sciences, Kerman-

shah University of Medical

Sciences, Kermanshah,

Iran

*Corresponding author:

M. Najafi

Radiology and Nuclear

Medicine Department,

School of Paramedical

Sciences, Kermanshah

University of Medical

Sciences, Kermanshah,

Iran

E-mail: najafi_ma@

yahoo.com

Received: 27 May 2018

Accepted: 14 July 2018 
agents [2]. Clastogenic agents such as ionizing radiation can damage genomic contents of these cells leading to cells death. In addition, damage to these cells may lead to persistent changes such as epigenetic modulation of some gene expressions, which can be transferred to subsequent generations [3].

It is well known that spermatogenesis system is one of the most radiosensitive organs in the body. A usual therapeutic dose of conventional radiotherapy ( 2 Gy in each fraction) has potent detrimental effects on spermatogenesis. Even lower doses of ionizing radiation seen in diagnostic radiology can affect spermatogenesis. Exposure to radiation with a sub-lethal dose during a radiation disaster is another indication for inhibition or potent injury on sperm counts, seminiferous tubules and spermatogenesis cell division [4]. Leyding cells are another type of cells in the testis supporting spermatogenesis procedure via hormone secretion such as testosterone. Although, these cells are more resistant to clastogenic effects of ionizing radiation, the detrimental effects on them have been proposed as a mechanism for spermatogenesis arrest [5].

Selenium and zinc are two important elements playing key roles in the development and maturation of sperm. Zinc deficiency has a direct relation with testicular growth suppression, damage to tubular epithelium and sperm counts. Therefore, decreased level of zinc affects pituitary gonadotrophins and testosterone hormones [6]. In addition to the crucial role of zinc in sperm development, it has shown protective effects against toxic agents, including ionizing radiation [7]. Zinc has the ability to activate superoxide dismutase (SOD) and enhance free radical scavenging by antioxidant defense of cells [8]. Floersheim et al. proposed that zinc has a similar radioprotective effect on some thiol agents, including cysteamine S,2- aminoethylisothiourea [9]. Similar to zinc, selenium has shown the involvement in the process of spermatogenesis as well as radioprotective effects against ionizing radia- tion. Dietary supplement with selenium has shown improved sperm motility and semen quality, leading to an increase in fertility [10]. In addition, selenium as an important element in the activity of glutathione peroxidase (Gpx) plays a key role in protection of cells against oxidative injury [11]. In response to ionizing radiation, treatment with a low dose of selenium has shown the ability to increase the expression of different subfamilies of GPx up to 2 fold, and attenuate genotoxicity in spleen and intestine [12].

Since both selenium and zinc have radioprotective properties and been involved in spermatogenesis, it aims to evaluate their possible protective effects against radiation-induced testicular injury in mice.

\section{Material and Methods}

\section{Experimental design}

This experimental study involved 30 mice ( $30 \pm 5$ gr) which were divided into 6 groups ( 5 mice in each group), including control without any contravention, zinc treatment, selenium treatment, radiation, radiation + zinc, radiation + selenium in order. All mice were kept under suitable conditions of temperature and humidity $\left(22{ }^{\circ} \mathrm{C}, 55 \%\right)$, light/dark cycle as 12 hours light (5AM-5PM) and 12 hours dark (5PM-5AM). Before irradiation, mice were anesthetized using an appropriate dose of ketamine and xylazine. All mice were killed 37 days after irradiation. Afterwards, their right testis was extracted after abdomen opening and immediately fixed in $10 \%$ normal buffer formalin.

\section{Drug treatment and irradiation}

Selenium was purchased from Webber natural (Canada) and dissolved in distilled water to obtain the concentration of $0.05 \mathrm{mg}$ per milliliter. Zinc (Nature Made, USA) was dissolved in distilled water with the concentration of 2 $\mathrm{mg}$ per milliliter. Selenium and zinc were administered as a dose of $0.8 \mathrm{mg} / \mathrm{kg}(0.5 \mathrm{ml})$ and 
Radioprotective Effects of Zinc and Selenium

$30 \mathrm{mg} / \mathrm{kg}(0.5 \mathrm{ml})$, respectively. These drug doses were selected based on previous studies $[13,14]$. Treatment with selenium or zinc started 2 days before irradiation up to the day of irradiation. The last doses of drugs were administered 30 minutes before irradiation. Irradiation of group's 4-6 mice was done using a cobalt-60 gamma rays source stationed at Imam Khomeini Hospital, Tehran University of Medical Sciences. All rats were irradiated by 2 Gy gamma rays at a dose rate of $50 \mathrm{cGy} /$ $\min$.

\section{Histopathological evaluation}

After fixation, testis tissues were embedded in paraffin and sections were cut at 0.4-micron thickness. Afterwards, slides were provided and stained with hematoxylin and eosin (H\&E). Morphological parameters such as spermatogenic arrest, atrophy of seminiferous tubules, thickening of basal lamina, leydig cell hyperplasia, edema, epididymis decreased sperm density, and epididymis vacuolation and
Johnsen scoring were evaluated by a pathologist. These parameters were scored from 1 to 4, while Johnsen scoring was from 0 to 10 .

\section{Statistical analysis}

All results were analyzed using SPSS software version 24 (IBM, Chicago, USA). Differences between groups were evaluated using ANOVA as well as Tukey's HSD post hoc test. $P$ value $<0.05$ was considered statistically significant.

\section{Results}

As shown in Table 1, treatment with selenium did not cause any cytotoxic effects on the testis. Results of this group was completely similar to the control group; however, treatment with zinc led to significant detrimental effects on spermatogenesis. Although Zinc treatment did not cause any significant effects on spermatogenic arrest, basal lamina and leydig cells, its effect was significant on epididymis. Results showed that irradiation of mice

Table 1: Results of radiation effects and treatment with selenium or zinc on spermatogenesis parameters. Histological parameters were scored from 0-4 and Johnsen scoring ranged from 0-10.

\begin{tabular}{|c|c|c|c|c|c|c|}
\hline & Control & Zinc & Selenium & Rad & Rad+Sel & Rad+Zinc \\
\hline Spermatogenic arrest & $0.00 \pm 0$ & $0.00 \pm 0$ & $0.00 \pm 0$ & $\mathrm{a} 1.00 \pm 0$ & ${ }^{\mathrm{b}} 0.00 \pm 0$ & $0.75 \pm 0.5$ \\
\hline $\begin{array}{c}\text { Atrophy of seminiferous } \\
\text { tubules }\end{array}$ & $0.00 \pm 0$ & $1.00 \pm 0.57$ & $0.00 \pm 0$ & $\mathrm{a} 1.25 \pm 0.5$ & ${ }^{\mathrm{b}} 0.00 \pm 0$ & ${ }^{c} 2.50 \pm 0.57$ \\
\hline $\begin{array}{l}\text { Thickening of basal } \\
\text { lamina }\end{array}$ & $0.00 \pm 0$ & $0.33 \pm 0.57$ & $0.00 \pm 0$ & a2.00 0.81 & ${ }^{\mathrm{b}} 0.25 \pm 0.5$ & ${ }^{\mathrm{b}} 0.25 \pm 0.5$ \\
\hline Leydig cell hyperplasia & $0.00 \pm 0$ & $0.33 \pm 0.57$ & $0.00 \pm 0$ & a2.25 250.50 & ${ }^{b} 1.00 \pm 0$ & $2.50 \pm 0.57$ \\
\hline Edema & $0.00 \pm 0$ & $0.33 \pm 0.57$ & $0.00 \pm 0$ & a $1.50 \pm 0.57$ & $1.25 \pm 0.5$ & $1.25 \pm 1.25$ \\
\hline $\begin{array}{l}\text { Epididymis decreased } \\
\text { sperm density }\end{array}$ & $0.00 \pm 0$ & ${ }^{a} 2.33 \pm 0.57$ & $0.00 \pm 0$ & ${ }^{\mathrm{a}} 4.00 \pm 0$ & $\mathrm{~b} 1.75 \pm 0.5$ & b2.75 \pm 0.5 \\
\hline Epididymis vacuolation & $0.00 \pm 0$ & ${ }^{a} 1.33 \pm 0.57$ & $0.00 \pm 0$ & a2.75 \pm 0.50 & ${ }^{b} 1.00 \pm 0$ & $2.66 \pm 0.57$ \\
\hline Johnsen scoring & $9.00 \pm 0$ & ${ }^{a} 6.66 \pm 0.57$ & $9.75 \pm 0.5$ & ${ }^{a} 4.00 \pm 0.81$ & ${ }^{b} 7.00 \pm 0.81$ & ${ }^{\mathrm{b}} 6.00 \pm 0$ \\
\hline $\begin{array}{l}\text { Number of spermatogonia } \\
\text { per tubules }\end{array}$ & $171.66 \pm 34$ & $149.66 \pm 4.64$ & $175 \pm 6.37$ & a $87 \pm 4.54$ & b181.33 \pm 1.24 & b149.33 \pm 5.25 \\
\hline
\end{tabular}

a: A significant increase compared to control group

$\mathrm{b}$ : A significant reduction compared to radiation group

c: A significant increase compared to radiation group 
with 2 Gy gamma rays led to a potent effect on spermatogenic arrest, atrophy of seminiferous tubules, thickening of basal lamina, leydig cell hyperplasia, edema, epididymis decreased sperm density and epididymis vacuolation. Therefore, irradiation caused a significant decrease in Johnsen scoring. Treatment with selenium reversed the damage significantly except edema; however, treatment with zinc only caused protection of basal lamina, epididymis and Johnsen scoring. Treatment with zinc potentiated damage to seminiferous tubules when treated before irradiation. In addition, treatment with zinc alone without exposure to radiation reduced Johnsen scoring and caused damage to epididymis in comparison with control group. Exposure to radiation led to severe reduction of spermatogonia, while treatment with selenium or zinc reversed it. The complete results are presented in Table 1, Figure 1.

\section{Discussion}

As earlier mentioned, testis is one of the most radiosensitive organs that is potentially affected by diagnostic and therapeutic doses of ionizing radiation. Moreover, accidental exposure to ionizing radiation during a radiological terror or nuclear disaster can lead to temporary or permanent infertility. Several natural and chemical agents have been studied for protection of animal testis against ionizing radiation by now. Radioprotective effects of natural antioxidants such as ascorbic acid, alpha-tocopherol, melatonin, and hesperidin have been studied [15-18]. In present study, we aim to evaluate the radioprotective effects of two natural body antioxidant, including selenium and zinc.

As the results have shown, irradiation of mice with 2 Gy gamma rays (as a topical dose in radiotherapy or radiation disasters) caused the potent damage to the testis. The most obvi-

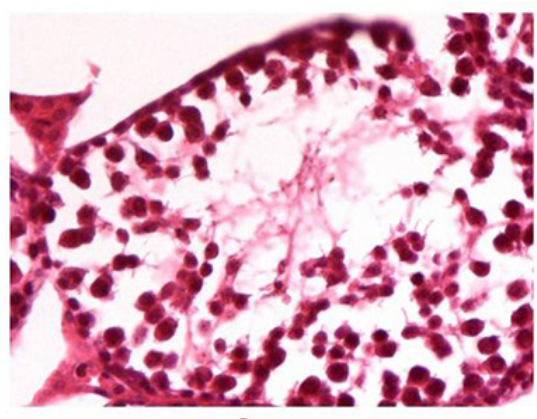

A

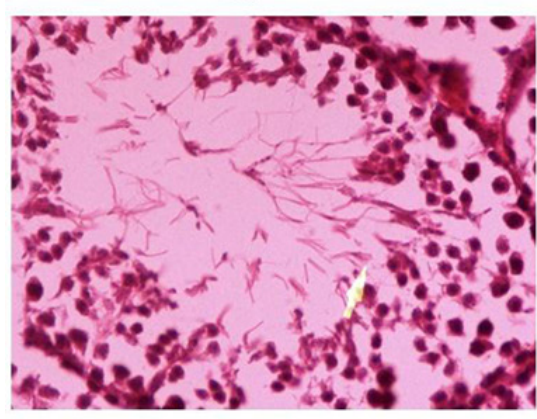

D

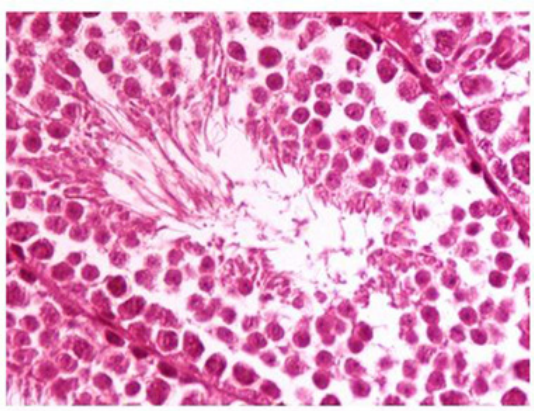

B

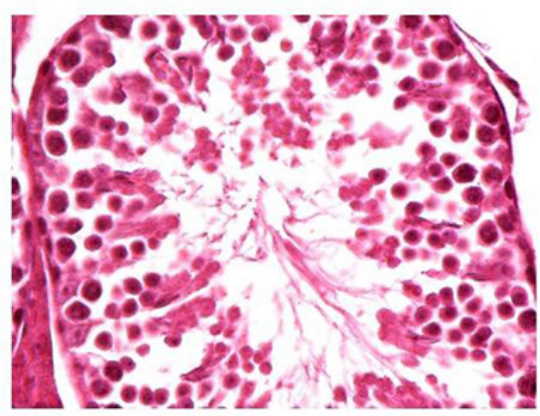

F.

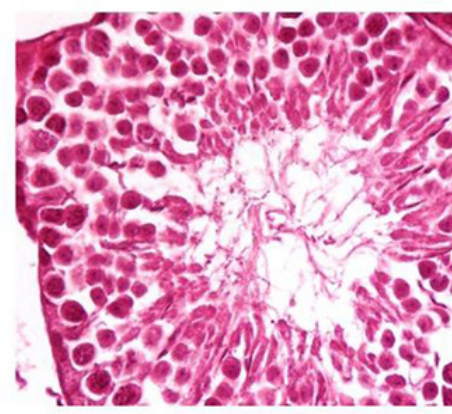

C

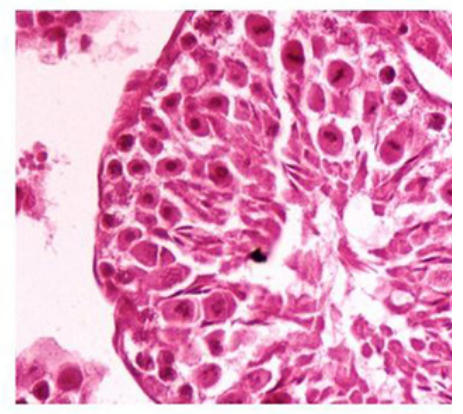

$\mathbf{F}$

Figure 1: Results of radioprotective effect of selenium or zinc on mice spermatogenesis system. A: Control; B: Zinc treatment; C: Selenium treatment; D: Radiation; E: Radiation plus Zinc; F: Radiation plus Selenium. Irradiation led to severe reduction of germ cells, while zinc attenuated decreased numbers of germ cells, and selenium completely reversed radiation toxicity (H\&E staining $\times 40$ ). 
ous damage was observed in the epididymis. Furthermore, basal lamina and leydig cells were damaged severely, while Johnsen score was reduced potently. Other parameters were mildly affected. Selenium treatment could protect mice testis from radiation toxicity on all parameters except edema. For some parameters such as spermatogenic arrest and atrophy of seminiferous tubules, selenium could inhibit radiation toxicity completely. These parameters for radiation plus selenium treatment were similar to the control group. These results may indicate that selenium is a potent antioxidant that is able to neutralize most free radicals produced by ionizing radiation; however, it could not prevent inflammation. In recent years, some studies have shown that selenium has ability to potently mitigate radiation toxicity in various organs such as hematopoietic and gastrointestinal system as well as kidney $[19,20]$. Since reduction/oxidation reactions are involved in radiation-induced oxidative injury, it seems that selenium via modulation of GPx enzyme attenuates both early and late effects of ionizing radiation [21].

In contrast to selenium, zinc has shown that it is not an appropriate radioprotector for spermatogenesis protection against radiation. Zinc treatment in a common dose (based on previous studies) led to toxicity in mice testis. This toxicity was significant for epididymis leading to decreased sperm density and epididymis vacuolation. Furthermore, Johnsen scoring was reduced while seminiferous tubules were affected. The severity of these parameters after zinc treatment was intermediate between the control and radiation groups. Moreover, when zinc was administered before irradiation, the severity of damage to seminiferous tubules was potentiated. However, for some other parameters such as decreased numbers of spermatogonia and sperm, as well as basal lamina, zinc could attenuate radiation toxicity mildly. Similar to selenium, zinc has ability to stimulate antioxidant enzymes. The main mediator of antioxidant effect of zinc is $\mathrm{Cu} /$
Zn-SOD. However, studies have shown that it attenuates radiation injury via increased activity of other antioxidant enzymes such as reduced glutathione (GSH) and glutathione reductase (GR) [22], further studies are needed for confirmation and better understanding of our results.

\section{Conclusion}

Results of this study has shown that treatment with selenium before irradiation can protect spermatogenesis system potently. Results also indicated that the protective effect of selenium in the administered dose was without any cytotoxicity. Results for zinc is very different in comparison with selenium. Zinc treatment was associated with cytotoxicity in epididymis. In addition, when administered before irradiation, it potentiates seminiferous tubule damage. The radioprotective effect of zinc was lower than selenium, some parameters and not most of them. Results of this study showed that selenium has ability to reverse decreased number of spermatogonia and sperms completely.

\section{Acknowledgment}

This study was supported by Aja University of Medical Sciences, Tehran, Iran.

\section{Conflict of Interest}

None

\section{References}

1. Marjault HB, Allemand I. Consequences of irradiation on adult spermatogenesis: $\mathrm{Be}$ tween infertility and hereditary risk. Mutat Res. 2016;770:340-8. doi: 10.1016/j. mrrev.2016.07.004. PubMed PMID: 27919340.

2. Moreno SG, Dutrillaux B, Coffigny H. High sensitivity of rat foetal germ cells to low dose-rate irradiation. Int J Radiat Biol. 2001;77:529-38. doi: 10.1080/09553000010030211. PubMed PMID: 11304444.

3. Trasler JM. Epigenetics in spermatogenesis. Mol Cell Endocrinol. 2009;306:33-6. doi: 10.1016/j.mce.2008.12.018. PubMed PMID: 
Bagheri H., Salajegheh A., Javadi A. et al

19481683.

4. Coleman CN, Blakely WF, Fike JR, et al. Molecular and cellular biology of moderate-dose (1-10 Gy) radiation and potential mechanisms of radiation protection: report of a workshop at Bethesda, Maryland, December 17-18, 2001. Radiat Res. 2003;159:812-34.

5. Holdcraft RW, Braun RE. Hormonal regulation of spermatogenesis. Int J Androl. 2004;27:33542. doi: 10.1111/j.1365-2605.2004.00502.x. PubMed PMID: 15595952.

6. Hidiroglou M, Knipfel JE. Zinc in mammalian sperm: a review. J Dairy Sci. 1984;67:114756. doi: 10.3168/jds.S0022-0302(84)814162. PubMed PMID: 6378991.

7. Emami S, Hosseinimehr SJ, Taghdisi SM, Akhlaghpoor S. Kojic acid and its manganese and zinc complexes as potential radioprotective agents. Bioorg Med Chem Lett. 2007;17:458. doi: 10.1016/j.bmcl.2006.09.097. PubMed PMID: 17049858.

8. Veldwijk MR, Herskind C, Sellner L, et al. Normal-tissue radioprotection by overexpression of the copper-zinc and manganese superoxide dismutase genes. Strahlenther Onkol. 2009;185:517-23. doi: 10.1007/s00066-0091973-0. PubMed PMID: 19652935.

9. Floersheim GL, Floersheim P. Protection against ionising radiation and synergism with thiols by zinc aspartate. $\mathrm{Br} J$ Radiol. 1986;59:597-602. doi: 10.1259/0007-128559-702-597. PubMed PMID: 3518853.

10.Moslemi MK, Tavanbakhsh S. Selenium-vitamin $\mathrm{E}$ supplementation in infertile men: effects on semen parameters and pregnancy rate. Int J Gen Med. 2011;4:99-104. doi: 10.2147/ijgm.s16275.

11.Amini P, Kolivand S, Saffar H, Rezapoor S, Motevaseli E, Najafi M, et al. Protective effect of Selenium-L-methionine on radiationinduced acute pneumonitis and lung fibrosis in rat. Curr Clin Pharmacol. 2018. doi: 10.217 4/1574884714666181214101917.

12. Verma P, Kunwar A, Priyadarsini KI. Effect of Low-Dose Selenium Supplementation on the Genotoxicity, Tissue Injury and Survival of Mice Exposed to Acute Whole-Body Irradiation. Biol Trace Elem Res. 2017;179:130-9. doi: 10.1007/s12011-017-0955-9.

13.Boran C, Ozkan KU. The effect of zinc therapy on damaged testis in pre-pubertal rats. $\mathrm{Pe}$ - diatr Surg Int. 2004;20:444-8. doi: 10.1007/ s00383-004-1173-z.

14.Ayhanci A, Yaman S, Appak S, Gunes S. Hematoprotective effect of seleno-L-methionine on cyclophosphamide toxicity in rats. Drug Chem Toxicol. 2009;32:424-8. doi: 10.1080/01480540903130682. PubMed PMID: 19793036.

15.Khan S, Adhikari JS, Rizvi MA, Chaudhury NK. Radioprotective potential of melatonin against 60 Co $\gamma$-ray-induced testicular injury in male C57BL/6 mice. J Biomed Sci. 2015;22:61. doi: 10.1186/s12929-015-0156-9.

16.Mahdavi M, Mozdarani H. Protective effects of famotidine and vitamin $\mathrm{C}$ against radiation induced cellular damage in mouse spermatogenesis process. International Journal of Radiation Research. 2011;8:223.

17.Songthaveesin C, Saikhun J, Kitiyanant Y, Pavasuthipaisit K. Radio-protective effect of vitamin $E$ on spermatogenesis in mice exposed to gamma-irradiation: a flow cytometric study. Asian Journal of Andrology. 2004;6:331-6.

18.Shaban NZ, Zahran AMA, El-Rashidy FH, Kodous ASA. Protective role of hesperidin against $\gamma$-radiation-induced oxidative stress and apoptosis in rat testis. Journal of Biological Research-Thessaloniki. 2017;24:5.

19.Sieber F, Muir SA, Cohen EP, Fish BL, et al. Dietary selenium for the mitigation of radiation injury: effects of selenium dose escalation and timing of supplementation. Radiat Res. 2011;176:366-74. PubMed PMID: 21867430. PubMed PMCID: PMC3237945.

20.Sieber F, Muir SA, Cohen EP, North PE, et al. High-dose selenium for the mitigation of radiation injury: a pilot study in a rat model. Radiat Res. 2009;171:368-73. doi: 10.1667/00337587-171.3.368.

21.Puspitasari IM, Abdulah R, Yamazaki C, Kameo S, Nakano T, Koyama H. Updates on clinical studies of selenium supplementation in radiotherapy. Radiat Oncol. 2014;9:125. doi: 10.1186/1748-717X-9-125. PubMed PMID: 24885670. PubMed PMCID: PMC4073179.

22.Dani V, Dhawan DK. Radioprotective role of zinc following single dose radioiodine (131I) exposure to red blood cells of rats. Indian $J$ Med Res. 2005;122:338-42. PubMed PMID: 16394327. 